\title{
Surgical anatomy of the foot and ankle
}

\author{
Andrew A. Amis $\cdot$ Peter A. J. de Leeuw • \\ C. Niek van Dijk
}

Published online: 20 March 2010

(c) The Author(s) 2010. This article is published with open access at Springerlink.com

Any operative intervention consists of two elements: the approach and the actual procedure itself. The actual procedure can be practised on sawbones or joint models [8], but the approach is mostly practised on patients. The learning curve for the approach is steep. In the past, surgeons made wide exposures and thus practised their anatomical skills on a day-to-day basis. With the introduction of minimally invasive and arthroscopic surgery, we learned to avoid the anatomy. We go straight to the bone and feel comfortable once inside a joint. Our incisions for open procedures get smaller and smaller. The patients like it if their surgical scars are very small, and there is some evidence that minimally invasive approaches can lead to shorter stays in hospital and to more rapid restoration of function, but our knowledge of the anatomy thus gets more and more forgotten. Our knowledge dates from anatomy books, which are, however, not specifically designed for surgical approaches.

A session in the cadaver laboratory can be extremely helpful to refresh our memories of the surgical anatomy approaches. It is important to know 'what is around the corner', especially in cases where an extended or unusual approach is needed. Foot and ankle surgeons who do not

\section{A. A. Amis}

Mechanical Engineering Department,

Imperial College London, London SW7 2AZ, UK

e-mail: a.amis@imperial.ac.uk

\section{P. A. J. de Leeuw · C. N. van Dijk (ه)}

Department of Orthopaedic Surgery,

Academic Medical Centre, University of Amsterdam, PO BOX 22700, 1100 DE Amsterdam, The Netherlands

e-mail: c.n.vandijk@amc.nl

P. A. J. de Leeuw

e-mail: p.a.deleeuw@amc.nl have access to anatomy specimens will find this issue of the journal helpful since it includes a series of papers on the theme of surgical anatomy of the foot and ankle [1-7]. These papers have arisen from an initiative by the ESSKA Basic Sciences Committee, who recognised the increasing interest and scientific work in the treatment of foot and ankle problems. Ultimately, all of orthopaedic surgery is based on the anatomy-not just the traditional anatomy that describes cadavers, but the anatomy that will be useful to the readers of this journal-the functional, or surgical, anatomy. The difference is that this has been written mostly by surgeons, for surgeons, and is intended to be useful as a guide for approaches to the structures, how to identify them, how to avoid trouble, how to understand their functional significance.

It might also be argued that, in order to link these anatomical papers more closely into functional relevance, they should be paired in the future with matching papers whose principal authors are biomechanical engineers, who can thus show the surgical readers the consequences of cutting specific structures or, therefore, which ones are the priorities for preservation or reconstruction during surgery, in order to restore the function of the foot and ankle complex as closely as possible to normality after injury or degenerative changes. Thus, a more comprehensive platform might also include data about the kinematics, stability, load-bearing characteristics of the joints and surrounding ligaments, tendons, muscles and fasciae.

Although it might sound extreme to some of our readers, suggesting that they should revisit the anatomy learned as the basis of their work, and also that they should augment it with the latest biomechanical knowledge, it could be debated that it is only by doing this that the surgeon is empowered to develop novel procedures, in order to overcome the limitations of current practice: 
an obvious example from the papers in this edition relates to access into the tibiotalar joint, a limitation to the design of ankle prostheses and their fixation. In order to ensure the level of expertise and rigour of the surgical anatomy articles in this issue of the journal, the authors also include an anatomist [5] and a biomechanical engineer [6]. These papers will be presented with many more illustrations in an Instructional Course at the ESSKA congress in Oslo, June 2010.

In the past, ESSKA has concentrated largely on the knee, with topics such as ACL reconstruction dominating. More recently, there has been increasing appreciation of the role of the function of the foot and ankle complex in affecting the biomechanics of the more proximal limb and joints; it cannot be ignored if a malalignment of the foot and ankle is the root of the knee problem. So we are pleased to present this series of papers and hope that they will act as part of a foundation for future work, both the everyday work of treating the traumatic and degenerative changes of the foot and ankle complex, but also to support researchers as they expand their investigation into this interesting and intricate mechanism. We hope that you will enjoy learning from the excellent illustrations, which these papers are presenting.

Open Access This article is distributed under the terms of the Creative Commons Attribution Noncommercial License which permits any noncommercial use, distribution, and reproduction in any medium, provided the original author(s) and source are credited.

\section{References}

1. Ahearne D, Rosenfeld P (2010) Surgical approaches to the forefoot for common sports related pathologies: a review of the literature and cadaveric dissection. Knee Surg Sports Traumatol Arthrosc 18. doi:10.1007/s00167-010-1096-2 (in press)

2. de Leeuw PAJ, Golano P, Sierevelt IN, van Dijk CN (2010) The course of the superficial peroneal nerve in relation to the ankle position; anatomical study with ankle arthroscopic implications. Knee Surg Sports Traumatol Arthrosc 18. doi:10.1007/s00167010-1099-z (in press)

3. de Leeuw PAJ, Golano P, Clavero JA, van Dijk CN (2010) Anterior ankle arthroscopy, distraction or dorsiflexion? Knee Surg Sports Traumatol Arthrosc 18. doi:10.1007/s00167-010-1089-1 (in press)

4. Doral MN, Alam M, Bozkurt M, Turhan E, Atay OA, Donmez G, Maffulli N (2010) Functional anatomy of the Achilles tendon. Knee Surg Sports Traumatol Arthrosc 18. doi:10.1007/s00167010-1083-7 (in press)

5. Golano P, Vega J, de Leeuw PAJ, Malagelada F, Manzanares MC, Götzens V, van Dijk CN (2010) Anatomy of the ankle ligaments: a pictorial essay. Knee Surg Sports Traumatol Arthrosc 18. doi: $10.1007 / \mathrm{s} 00167-010-1100$-x (in press)

6. Kleipool RP, Blankevoort L (2010) The relation between geometry and function of the ankle joint complex: a biomechanical review. Knee Surg Sports Traumatol Arthrosc 18. doi:10.1007/s00167010-1088-2 (in press)

7. Pearce CJ, Calder JD (2010) Surgical anatomy of the midfoot. Knee Surg Sports Traumatol Arthrosc 18. doi:10.1007/s00167010-1101-9 (in press)

8. Tuijthof GJ, van Sterkenburg MN, Sierevelt IN, van Oldenrijk J, Van Dijk CN, Kerkhoffs GM (2010) First validation of the PASSPORT training environment for arthroscopic skills. Knee Surg Sports Traumatol Arthrosc 18:218-224 